\title{
TEM Analysis of Impurity Induced Microstructures in Sintered Aluminium Nitride Ceramics
}

\author{
Serge HAGÈGE*, Yoichi ISHIDA and Shun-ichiro TANAKA**

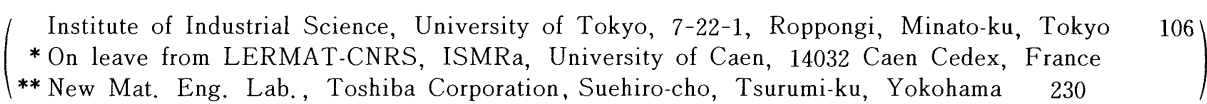

窒化アルミニウム焼結体中の偏析誘起組絨の電子顕微鏡解析

\author{
Serge Hagège*, 石田洋一, 田中俊一郎** \\ 東京大学生産技術研究所, 106 東京都港区六本木 7-22-1 \\ *CNRS (国立科学研究セン多一), Caen 大学, 14032 Caen Cedex France
** (株) 東芝新素材応用研究所, 230 横浜市鶴見区未広町
}

\begin{abstract}
Two AlN materials with different impurity contents have been studied by TEM. Impurities are found to modify the microstructure of the material by forming polytypoid grains, precipitates of $\mathrm{Al}_{2} \mathrm{O}_{3}$ and $\mathrm{FeAl}_{2} \mathrm{O}_{4}$. The $27 \mathrm{R}$ polytypoid is mostly present as a whole in one grain, but mixtures of polytypoids or compositional modulation are also found. Almina precipitates are either intragranular or at triple points. The spinel phase shows a perfect epitaxy with the polytypoid phase. Complicated arrangements of dome like defects are present in most AlN $2 \mathrm{H}$ grains and are chemically induced.
\end{abstract}

[Received April 22, 1988 ; Accepted September 16, 1988]

Key-words : AlN, TEM, Microstructure, Impurites, Interfaces, Stacking faults, Polytypoids

\section{Introduction}

It has been often demonstrated that the presence of impurities in a given ceramic material has a strong effect on the microstructure and more particularly on the nature of the interfaces. ${ }^{1)}$ In the case of aluminium nitride based ceramic materials, oxygen impurities play a major role on the microstructure by inducing stacking faults in the basal plane of AlN $2 \mathrm{H}$ polytypoids and dome like defects can also occur. ${ }^{2)}$

Silicon nitride and its related compounds; silicon aluminium oxynitrides or sialons, are representative ceramics for high temperature engineering applications. They are often described in the quarternary diagram $\mathrm{Si}_{3} \mathrm{~N}_{4}-\mathrm{AlN}-\mathrm{Al}_{2} \mathrm{O}_{3}$ $\mathrm{SiO}_{2} .{ }^{3)}$ The rich AlN corner of this diagram has been recently the subject of a number of microstructural studies ${ }^{4)-7)}$ obviously initiated by the good technological performances of AlN base ceramics. Aluminium nitride has a high thermal conductivity with a good electrical resistivity and a rather small thermal expansion coefficient. Thanks to their low reactivity to molten metals aluminium nitride ceramics are also used in metallurgy as crucibles and evaporator boats. These properties, combined with a good mechanical strength, give to AlN ceramic materials a large range of engineering applications, the most acknowledged one being as substrates for integrated circuits.

The purpose of this preliminary study has been to analyze, mainly by transmission electron microscopy, the microstructure of two commercially produced aluminium nitride containing different quantities of non-metallic (Oxygen $\cdots$ ) as well as metallic $(\mathrm{Fe}, \mathrm{Si}, \mathrm{Ca} \cdots)$ impurities. It will be suggested hereafter that the main characteristics of the microstructure and the nature of the structural defects are simply related to the presence of these impurity atoms inserted in the wurtzite structure of AlN $2 \mathrm{H}$. Different configurations of polytypoids and precipitates will be presented. The original feature of this material is a very particular configuration of stacking faults lying alternatively on the basal plane and on a curved three-dimensional surface.

\section{1 The wurtzite structure}

Aluminium nitride can be represented as in Fig. 1 (a) by a hexagonal close packed arrangement of aluminium atoms defining tetrahedral sites half filled by nitrogen atoms (wurtzite structure). It is traditional to represent the structure of wurtzite type materials by a projection on the $(11 \overline{2} 0)$ plane, as in Fig. 1(b), in order to characterize the 


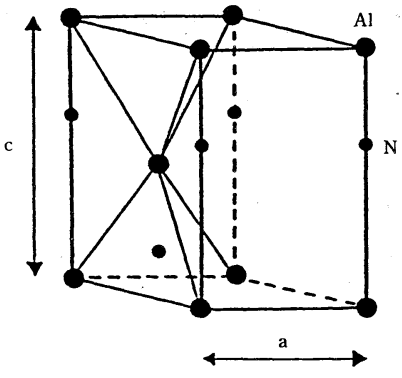

( a )

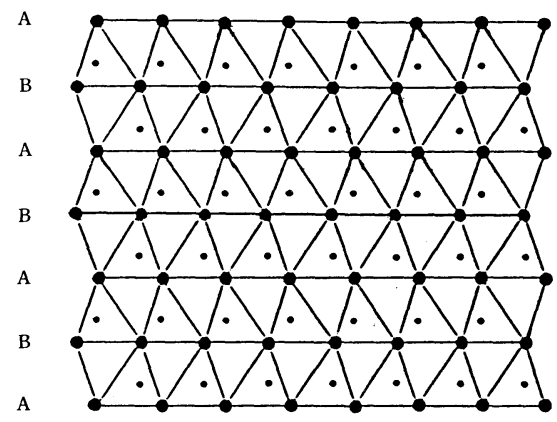

Fig. 1. AlN wurtzite structure.

(a) Unit cell with tetrahedral sites,

(b) $(11 \overline{2} 0)$ projection

hcp stacking of the basal planes.

\subsection{Stacking faults}

In the wurtzite structure one can distinguish single and double faults on the basal plane as in the hcp structure but with the difference that double layers of basal planes (aluminium A, B, C and nitrogen $a, b, c)$ have to be taken into account. ${ }^{8)}$ The layer sequence along the [0001] direction for a single fault is

\section{......AaBbAaBbCcBbCc......}

and contains one unit of the sphalerite arrangement. Such a fault cannot be generated directly by the movement of a Shockley partial, though it could be generated during growth. For a double fault on the basal plane the sequence is

$$
\text { ......AaBbAaBbCcAaCcAa...... }
$$

and contains two units of the sphalerite arrangement. This fault can be generated by the movement of a Shockley partial of the type $1 / 3$ $\langle 1 \overline{1} 00\rangle$ or in the basal part of the dome like defect. ${ }^{2)}$

\subsection{Influence of the Impurities}

Aluminium nitride based ceramic materials are

Table 1. Chemical composition

$\begin{array}{ccc}\text { element } & \mathrm{Al} & \mathrm{N} \\ \text { hot pressed } & 64.94 & 32.86 \\ \text { pressureless sintered } & 65.52 & 33.95\end{array}$

often found in combination with oxide type materials such as $\mathrm{Al}_{2} \mathrm{O}_{3}, \mathrm{SiO}_{2}, \mathrm{Y}_{2} \mathrm{O}_{3}$ etc. In the case of alumina, solid solutions between $\mathrm{AlN}$ and $\mathrm{Al}_{2} \mathrm{O}_{3}$ are very special in the sense they have aluminium as a common element and it is well accepted that the addition of oxygen to AlN would create impossibly short distances between atoms which is caused by the change of coordination of the metal atom. Therefore in the presence of a small quantity of oxygen impurities, AlN materials will contain, in addition to the wurtzite AlN $2 \mathrm{H}$, a large variety of modulated structures called compositional polytypes or polytypoids. The structure of these polytypoids has a well accepted model $^{4,7)}$ based on an adequate stacking of layers with various combinations of the coordination of the metal atom: coordination four as in $\mathrm{AlN}$, coordination six as in $\mathrm{Al}_{2} \mathrm{O}_{3}$ and once per unit blocks, one or two metallic layers are shared by two or three adjacent tetrahedral sites to compensate the excess of nonmetallic atoms. The coordination six is associated with a single stacking fault on the metallic layers.

\section{Experimental procedure}

The first specimen, produced by Toshiba Corporation, has been hot pressed for one hour at $1973 \mathrm{~K}$ under $220 \mathrm{~kg} / \mathrm{cm}^{2}$. It was black colored and therefore not transparent to the light. The second one, produced by Tosoh Corporation, has been pressureless sintered for three hours at 2073 $\mathrm{K}$. It is lightly colored and fairly transparent to the light. Chemical composition determination and X-ray analysis were performed on both specimens. They differ appreciably, as will be shown in details in the next paragraph. The TEM specimen were mechanically cut and thinned to approximatively $50 \mu \mathrm{m}$. Final electron transparency was obtained by ion beam thinning at 4.5 $\mathrm{kV}$. A JEM 1250 high voltage and $200 \mathrm{CX}$ high resolution microscopes were used for the observations.

\section{Results}

\subsection{Chemical composition}

Table 1 gives the chemical composition of the materials used for this study. Oxygen is the main nonmetallic impurity with a smaller amount of carbon, silicon, iron and calcium for a lesser percentage, can be considered as the main metallic impurities.

\subsection{X-ray analysis}

(weight\%) of the specimens.

$\begin{array}{ccccc}\mathrm{Si} & \mathrm{Fe} & \mathrm{Ca} & \mathrm{O} & \mathrm{C} \\ 0.24 & 0.40 & 0.018 & 1.43 & 0.11 \\ 0.005 & 0.001 & 0.008 & 0.15 & 0.04\end{array}$


The analysis of the X-ray profiles, presented in Fig. 2 showed that the pressureless sintered specimen contains only the AlN $2 \mathrm{H}$ phase.

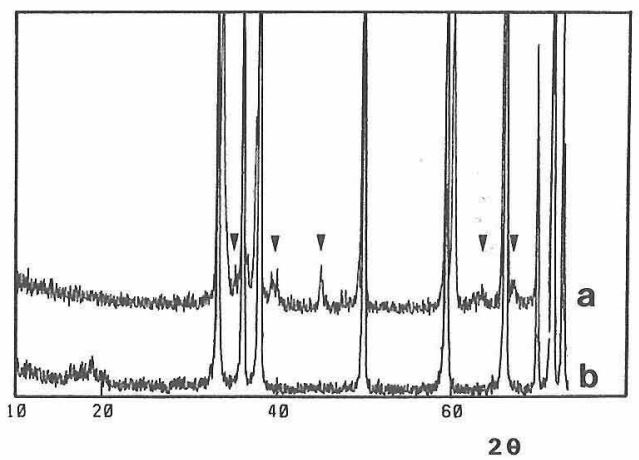

Fig. 2. X-ray analysis $(\mathrm{Cu} K \alpha)$ of the two specimen. (a) Hot pressed AlN,

(b) Pressureless sintered AlN

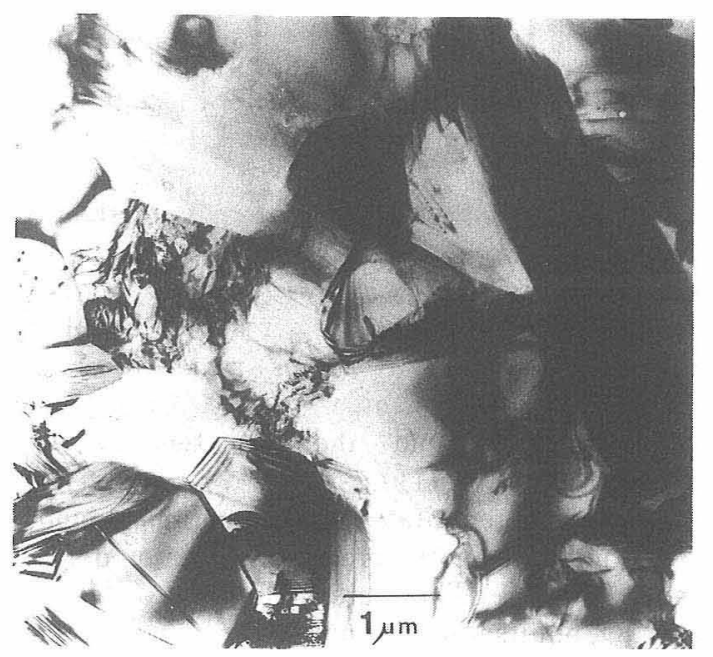

Fig. 3. Microstructure of the hot pressed AlN.
As expected from the chemical analysis, the hot pressed specimen contains, in addition to $\mathrm{AlN}$ $2 \mathrm{H}$, some other phases :

$$
\begin{array}{lr}
7 \mathrm{AlN} \cdot \mathrm{Al}_{2} \mathrm{O}_{3}, n=9 & \text { (hexagonal) } \\
\theta-\mathrm{Al}_{2} \mathrm{O}_{3} & \text { (monoclinic) }
\end{array}
$$
and with a lesser reliability:
$8 \mathrm{AlN} \cdot \mathrm{Al}_{2} \mathrm{O}_{3}, n=10$
$\mathrm{FeAl}_{2} \mathrm{O}_{4}$
(hexagonal)
(cubic spinel)

The presence of the hexagonal $7 \mathrm{AlN} \cdot \mathrm{Al}_{2} \mathrm{O}_{3}$ phase or $27 \mathrm{R}$ polytypoid was easily predictable from the amount of oxygen in the sample but we will show from the TEM results that complicated mixtures of polytypoids will have to be taken into account in order to understand the detection of the $8 \mathrm{AlN} \cdot \mathrm{Al}_{2} \mathrm{O}_{3}$ phase. The $\theta-\mathrm{Al}_{2} \mathrm{O}_{3}$ and $\mathrm{FeAl} \mathrm{O}_{4}$ phases have been found as precipitates in AlN matrix.

\section{3 Microstructure}

Figure 3 represents the typical microstructure of the hot pressed sample. AlN $2 \mathrm{H}$ grains are roughly equiaxed with an average size of a few microns. The polytypoids are always present in elongated grains with the basal plane parallel to the longest direction. Every grain has a large concentration of defects most probably introduced in the material by the pressure applied during the manufacturing of the specimen.

The pressureless sintered sample has a much simpler microstructure (Fig. 4) with only $\mathrm{AlN} 2 \mathrm{H}$ grains. Almost no defects were found in this sample. Most probably the combination of impurities and pressure during the preparation of the hot pressed speciment is responsible for the very different microstructures.

Inclusions of small $\theta-\mathrm{Al}_{2} \mathrm{O}_{3}$ grains were often found inside the AlN $2 \mathrm{H}$ grains of the hot pressed specimen (Fig.5(a)). Exceptionally large $\theta$ $\mathrm{Al}_{2} \mathrm{O}_{3}$ grains were also found between $\mathrm{AlN} 2 \mathrm{H}$

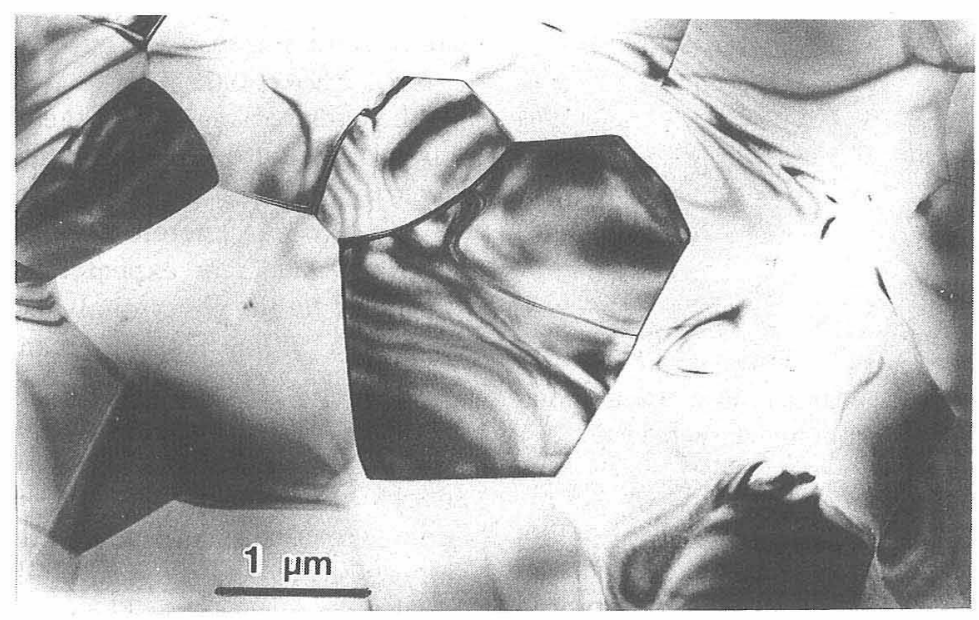

Fig. 4. Microstructure of the pressureless sintered AIN. 


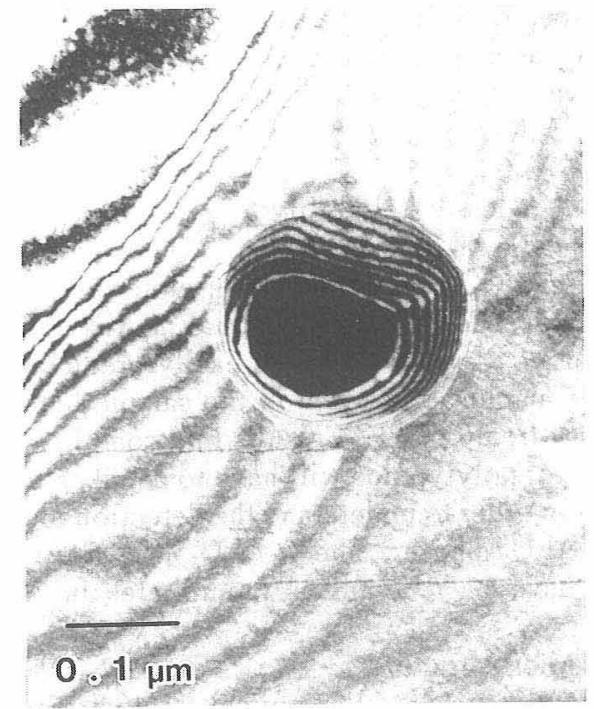

a

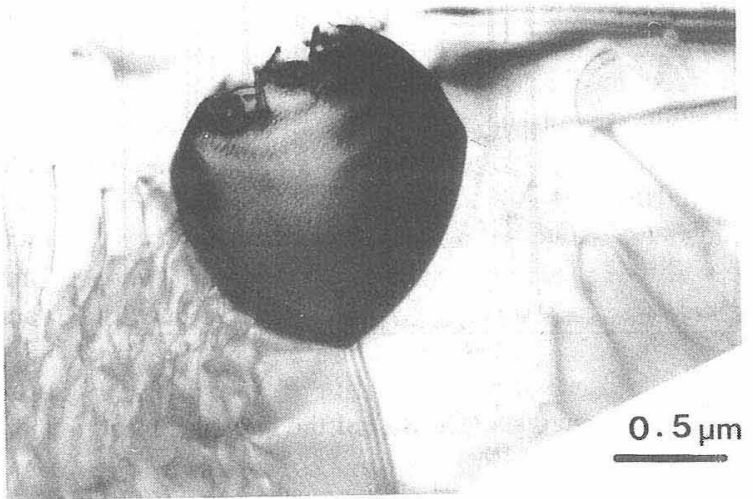

b

Fig. 5. Precipitates in the hot pressed specimen.

(a ) $\theta-\mathrm{Al}_{2} \mathrm{O}_{3}$ round shaped precipitate in an $\mathrm{AlN} 2 \mathrm{H}$ grain,

(b) $\theta-\mathrm{Al}_{2} \mathrm{O}_{3}$ precipitate at a triple point junction

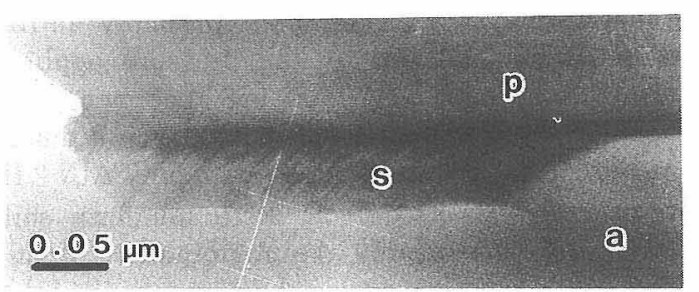

Fig.6. Epitaxial growth of the spinel phase $\mathrm{FeAl}_{2} \mathrm{O}_{4}$ from a polytypoid grain.

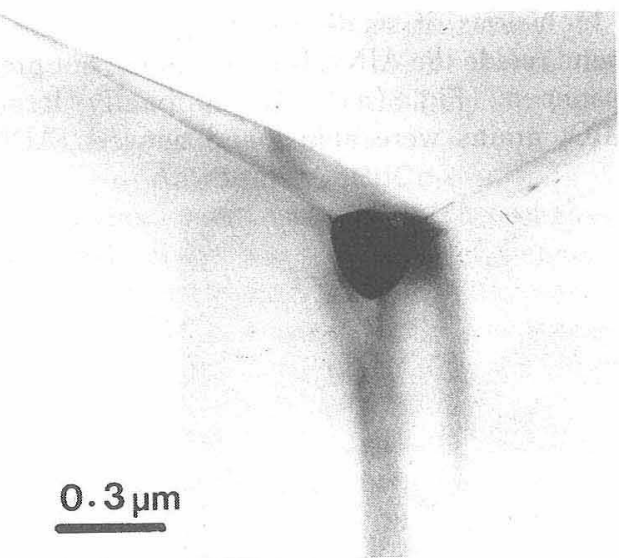

Fig. 7. Precipitation of alumina at a triple point junction of the pressureless sintered specimen.

grains at grain boundary junctions (Fig. 5(b)). The $\mathrm{FeAl}_{2} \mathrm{O}_{4}$ spinel phase was difficult to detect because it appears in the shape of a very small precipitates attached to one side of a polytypoid grains (Fig. 6). The $\theta-\mathrm{Al}_{2} \mathrm{O}_{3}$ inclusions never show any preferential orientation with the AlN $2 \mathrm{H}$ matrix or neighboring grains. On the contrary the $\mathrm{FeAl}_{2} \mathrm{O}_{4}$ phase is on perfect epitaxy with the polytypoid grain (Fig. 6(b)) and show the following orientation relationships with the matrix orientation relationships $[11 \overline{2} 0]_{\mathrm{M}} / /[110]$ and $[0001]_{M} / /[111]$ and that of the interface plane; $(0001)_{\mathrm{M}} / /(111)$.

Very tiny precipitates were sometimes found at triple junctions in the pressureless sintered specimen (Fig. 7). They are believed to be also $\theta-\mathrm{Al}_{2} \mathrm{O}_{3}$ but its total amount in the specimen is too low, to detect by X-ray. It should be emphasized nevertheless that these precipitates were seldom and that almost all triple points were exempt of the second phase.

\subsection{Polytypoids}

The chemcal analysis of the hot pressed sample has shown that oxygen was the main nonmetallic impurity. Its total concentration was nevertheless only $1.43 \mathrm{wt} \%$. Therefore, only polytypoids with high $n$ values are expected to be present. As predicted by the X-ray analysis, the $27 \mathrm{R}$ polytypoid was found most frequently in one grain (Fig. 8(a)) but some other polytypoid grains where often composed of a mixture of various unit blocks. In Fig. 8(b) the structure is made of unit blocks of 9,10 or 11 layers $(n=9,10,11)$. In order to form one unit cell of a particular polytypoid, two ( $n$ even) or three ( $n$ odd) unit blocks are necessary. Then in Fig. 8(b), at least some unit cells of the polytypoids $33 \mathrm{R}$ (3 unit 
blocks minimum) and $20 \mathrm{H}$ (2 unit blocks minimum) are present but in the middle part of the picture the mixture of unit blocks do not correspond to any particular complete polytypoid structure but appears as a compositional modulation.

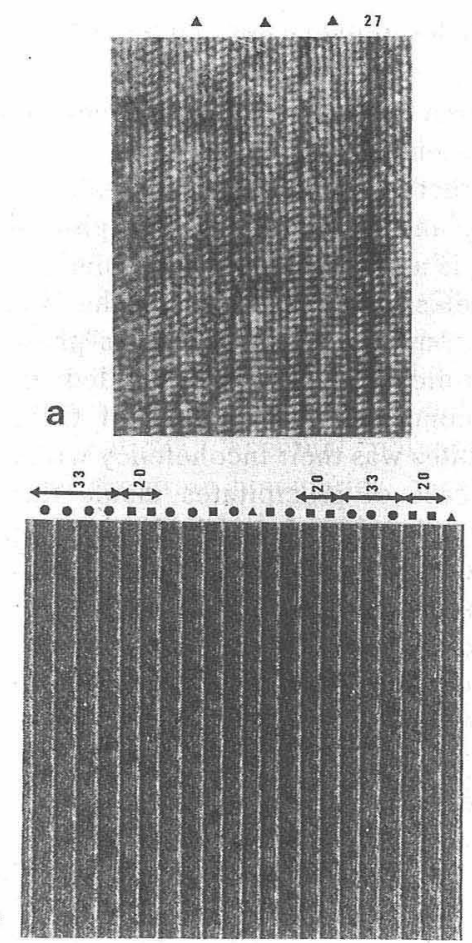

Fig. 8. HREM of polytypoids.

(a) $27 \mathrm{R}$ polytypoid grain, 3 units for $n=9$,

(b) Compositional modulation of the polytypoid structure in a grain.

Full triangles, squares and circles indicate respectively $n=9,10$ and 11 units.
This modulated structure may have been counted as the phase $8 \mathrm{AlN} \cdot \mathrm{Al}_{2} \mathrm{O}_{3}(n=10)$ in the $\mathrm{X}$-ray analysis.

\subsection{The dome-like defects}

In a large number of AlN $2 \mathrm{H}$ grains, arrangements of faults are present and show a very particular configuration (Fig.9). They are formed by two types of surfaces, one flat lying in

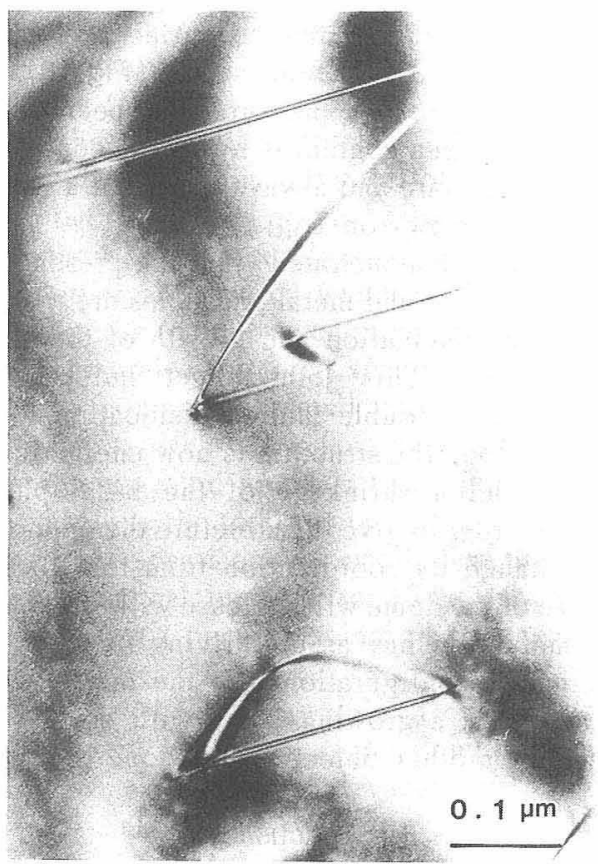

Fig. 9. Several "dome" configurations within an AlN $2 \mathrm{H}$ grain.

Lower part: one single dome,

Upper part : interaction of three single dome showing a simple zig-zag configuration.

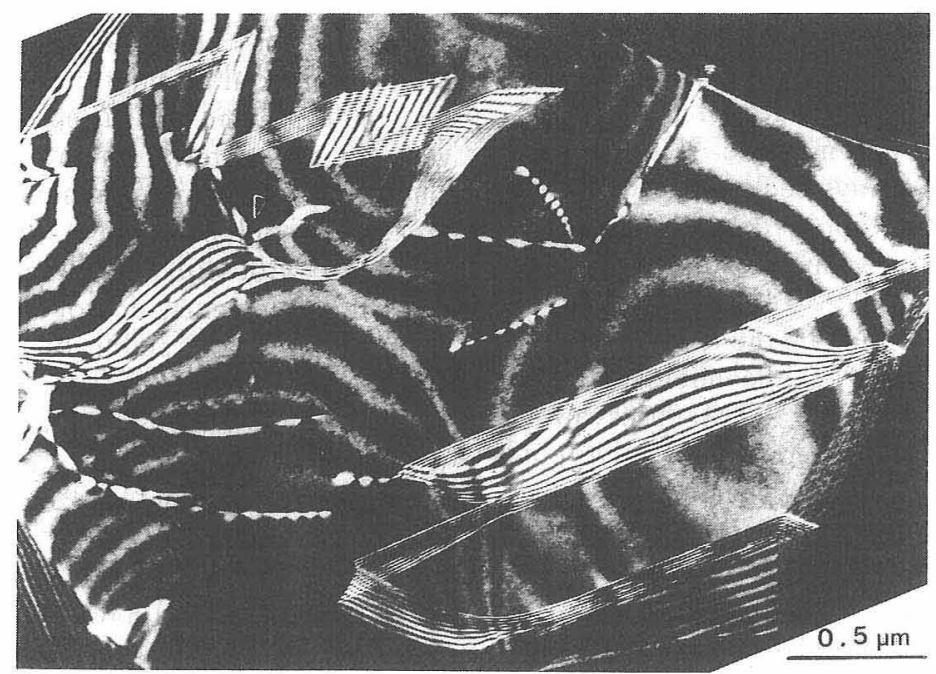

Fig. 10. Two complicated configurations of dome like defects within on AlN $2 \mathrm{H}$ grain of the hot pressed specimen. The wavy part of the upper configuration has been impinged by a dislocation node (see arrow). 
the basal plane and one curved, two different surfaces being connected by a dislocation. In the most simple cases the configuration is like a "dome" which is made of a dislocation loop containing a stacking fault and surmounted by a rather spherical faulted surface. Most of the time, in the hot pressed specimen, these configurations are more complicated but are always composed by a continuous sequence of one basal fault, one dislocation, a curved faulted surface, one dislocation, a basal fault and so on (Fig.10).

In the case of the pressureless specimen in which the oxygen content is low these configurations are very rare and always remain at a simple shape (see arrows on Fig. 4).

It has been demonstrated ${ }^{9)}$ that the presence of oxygen impurity and metal vacancies are the key point of the nucleation and growth of the dome configuration. This joint effect induces the formation of a double faulted dislocation loop. Inside the loop the structure is now energetically unstable and a shrinkage of the basal planes occurs in order to give the structure the opportunity to change its coordination from four to six. The size of the dome will increase with supersaturated metal vacancy as the driving force. More complicated configurations are the result of the interaction of a growing dome with matrix dislocations or other defects within one grain.

\section{Discussion}

In this report we have conducted several analysis and TEM observations in order to understand the various effects of impurities on the microstructure and therefore the properties of aluminium nitride ceramic materials. It has been well established that the addition of silicon and oxygen to aluminium nitride can be described in the quaternary system $\mathrm{Si}_{3} \mathrm{~N}_{4}-\mathrm{AlN}-\mathrm{Al}_{2} \mathrm{O}_{3}-\mathrm{SiO}_{2}$. In the case of AlN rich compounds the effects of metallic ( $\mathrm{Si}$, $\mathrm{Fe}, \mathrm{Ca}$ etc.) and non-metallic (O, C etc.) impurity atoms* has always been reported through the formation of polytypoid compounds in the quarternary system as summarized in paragraph 2. 3 .

Our first result will then be the confirmation of this effect of impurities on the microstructure. The X-ray analysis and the TEM obsesvations have detected a large amount of polytypoid compounds in the hot pressed specimen and none in the pressureless one. One original aspect of this work would have been the presence of

* The general use of the terms "metallic and nonmetallic" impurities cannot be taken here on the strict sense but with a wider acceptation as similar to the metal $\mathrm{Al}$ for $\mathrm{Si}, \mathrm{Ca}$, $\mathrm{Mg}, \mathrm{Fe}$ etc. and similar to the nonmetal $\mathrm{N}$ for $\mathrm{O}, \mathrm{C}$ etc. complicated mixtures $(n=9,10,11)$ or compositional modulation within one grain, result which could be misleading $(n=10)$ when taking into account only the X-ray analysis.

A more important result is related to the formation in the hot pressed specimen of precipitates. Two types were detected : $\theta-\mathrm{Al}_{2} \mathrm{O}_{3}$ and $\mathrm{FeAl}_{2} \mathrm{O}_{4}$.

The first ones were the most frequent ones and were present in various sizes and locations in the microstructure. These precipitates were characterized by an unusual crystallographic phase : the $\theta-\mathrm{Al}_{2} \mathrm{O}_{3}$ is a metastable form of alumina which has nevertheless been reported in the literature on similar conditions in the niobium phase near the alumina-niobium diffusion bonded interface. ${ }^{10)}$ The second important aspect of these alumina precipitates was their incoherency with the matrix in the case of precipitates inside the $\mathrm{AlN} 2 \mathrm{H}$ grains and with the neighbouring grains for intergranular precipitates. Then, these precipitates were often surrounded by a higher concentration of defects and will also impinge the growth of the dome like defect leading to an accumulation of strain within a small area.

It is reasonable to assume that the alumina precipitates are due to the presence of oxygen in the material. This oxygen may have come from various sources but in the case of the hot pressed specimen it mainly originated from $\alpha$ alumina addition during the material preparation. But, from the presence of the $\theta$ form of alumina in the precipitates, we may conclude, by analogy with the work presented in, ${ }^{10)}$ that a dissolution precipitation phenomena has occurred at some stage of the specimen preparation.

The spinel phase $\mathrm{FeAl}_{2} \mathrm{O}_{4}$ was always found attached to the side of a polytypoid grain and in perfect epitaxial orientation. Such a morphology may let us assume that the spinel phase could be a way for the material to integrate an excessive amount of iron which cannot be incorporated in the polytypoid compound. Iron atoms, at the difference with silicon, calcium, magnesium and other light elements, do not replace easily aluminium atoms in the sialon or related materials. ${ }^{3)}$

Then, in the presence of a rather large amount of impurities of various type, polytypoid grains will be formed by using silicon and, probably, calcium on one hand and oxygen on the other hand. Precipitates will be generated from the excess amount of oxygen and sometimes iron in the material and will have the same global effect on the properties as the polytypoids grains. Obviously, due to its higher purity none of these effect has been observed on the pressureless 
sintered specimen with the only exception of the very tiny alumina precipitates occasionally found at triple point junction. Despite of its purity, the pressureless sintered material did contain some oxygen.

Obviously our two materials did not receive the same treatment for their preparation. If the temperatures are relatively close, the lengths of time are quite different and more important, one was pressureless sintered as the other one was submitted to a relatively high pressure (220 $\left.\mathrm{kg} / \mathrm{cm}^{2}\right)$. However we still believe that these differences in preparation condition will not affect drastically the differences of microstructure we have been describing. Their main consequences will be related to the amount of deformation and its usual consequences; density and mobility of the dislocations, eventual polygonisation, migration of the grain boundaries, faceting etc. The microstructure itself i.e. the number, the type and the morphology of the phases present in the two materials will only be slightly affected by these differences in specimen preparation. The chemistry will play the major role. Then this difference of morphology between our two specimens could help us in the understanding of the effect of each type of impurities on the microstructure. We will discuss this point hereafter.

Preliminary results on the dome like defect have already been reported by the authors. ${ }^{2)}$ It was then assumed that oxygen impurities were the main cause of the nucleation and growth of these defects leading to complicated configurations when interacting with each other and with other defects, such as dislocations and precipitates. Then, one point, at least, would have to be clarified. Oxygen impurities are meant to induce polytypoid grains as well as dome like defects. But, all the observations on the hot pressed specimen have shown a very separate morphology with polytypoid grains without any dome like defect and a vast majority of AlN $2 \mathrm{H}$ grains containing various amount of dome like defect, without any trace of stacking faults related to the polytypoid phases.

A first answer to this discrepancy could be associated to the difference of oxygen content within one single grain. For low content dome like defects can be formed for they need rather small amount of oxygen to nucleate and grow. ${ }^{9)}$ In both materials studied in this report they were found, even though they were very few in the pressureless sintered specimen. For higher content of oxygen the number of stacking faults rapidly increases and polytypoid grains can be formed. It can be assumed that this explanation is partly true but, nevertheless, it cannot be completely satisfactory. This cause only, will assume a large heterogeneity of the oxygen content within the materials: high concentration in some area inducing polytypoid grains and low concentration is some other area leaving AlN $2 \mathrm{H}$ grains with dome like defects. This will be also, somehow, contradictory to the common observation of $\theta$ $\mathrm{Al}_{2} \mathrm{O}_{3}$ precipitates within AlN $2 \mathrm{H}$ grains containing also some dome like defects.

A second more important contradiction is related to the type of stacking fault necessary to form the dome like structure, double stacking fault created within a dislocation loop, different from the polytypiod grains based on the periodical repetition of a single stacking fault.

Another observation which could be useful to recall is the total absence of polytypoid grains in the pressureless sintered specimen which nevertheless contains a small amount of oxygen. However some, very few but some, alumina precipitates were found at triple point junction. In addition, the total content of metallic impurities in the specimen was small, less than $15 \mathrm{ppm}$ for silicon, calcium and iron. The amount of iron alone being $1 \mathrm{ppm}$ the spinel phase has not been detected.

If an AlN $2 \mathrm{H}$ grain contains a certain amount of oxygen still in solution in the structure and if this can induce enough metal vacancies, dome like defects can nucleate and grow.

If an aluminium nitride material contains, in addition to oxygen, also some metallic impurities such as silicon, calcium and often in other cases magnesium, lithium or some other light element, the formation of polytypoid grains is possible. The presence of these metallic impurities seems to be an imperious necessity for the formation of a bimodal microstructure. It should be added that oxygen are most probably also present within the grain when the polytypoid transformation is undergone but the coexistence of metallic impurities seems to be the major factor. In the case of our hot pressed specimen, silicon and calcium are present in certain grain at a sufficient level to form polytypoid grains. It can be asserted that some iron is also present in the polytypoid phase but a large part of iron atoms will be concentrated at the spinel phase precipitates. In the case of the pressureless specimen the total amount of metallic impurities is too low to form either polytypoid grains nor spinel phase precipitates.

It looks more evident that impurities will drastically change the microstructure of aluminium nitride ceramic materials with every type of element having a precise and well defined effect 
on the microstructure. These effects can also be related to the properties of this type of engineering materials with an expected large difference in the mechanical properties in favour to the hot pressed specimen and in the optical and thermal properties in favour to the pressureless sintered specimen.

\section{Conclusion}

By comparing the microstructure and the properties of two different aluminium nitride ceramic materials we have been able to determine the influence of every type of impurity element on the structural defects. Large oxygen concentration will occur at the $\theta$-alumina precipitates with various morphology. Dome like defects and more complicated configurations will be created when the oxygen content in an AlN $2 \mathrm{H}$ grain is sufficient. Metallic impurities as silicon and calcium will induce the formation of polytypoids grains whereas iron impurities are likely to concentrate on spinel phase precipitates. In varying the type and the content of these impurities in aluminium nitride type ceramic materials one can drastically change the microstructure from a black specimen with a bimodal morphology and to a fairly translucent monophase specimen with almost precipitate free AlN $2 \mathrm{H}$ grains.

Acknowledgments We are very thankful to Dr. Kuramoto from Tokuyama Soda for providing the "shapal" specimen. The discussions with Dr. Y. Bando (NIRIM) on the structure of the polytypoid phase were most enlightening. One of us (S.H.) would like to acknowledge the french CNRS for making possible an extended sojourn in Japan and sincerely thank the Institute of Industrial Science for a particularly warm welcome.

\section{References}

1) Grain Boundary Structure and Related Properties, Ed. Y. Ishida, Proceedings of the JIMIS IV symposium (1986).

2) S. Hagège, Y. Ishida and S. Tanaka, Proceedings of ISE 87, to be published in $J$. de Phys. (1988).

3) K. H. Jack, J. Materials Science, 11, 1135 (1976).

4) D.P. Thomson, P. Korgul and A. Hendry, "Nitrogen Ceramics", Ed. F.L. Riley (1983) p. 61.

5) G. Van Tendelloo, K. T. Faber and G. Thomas, $J$. Materials Science, 18, 525 (1983).

6) K. M. Krishnan, R.S. Rai, G. Thomas, N. D. Corbin and J.M McCawley, Mat. Res. Soc. Symp. Proc. Vol. 60, 211.

7) Y. Bando, M. Mitomo, Y. Kitami and F. Izumi, Journal of Microscopy, 142, 235 (1986).

8) S. Amelincks, "Dislocations in Solids", Ed. F. R. N. Nabarro (1979).

9) S. Hagège and Y. Ishida, submitted to the Journal of the Japanese Institute of Metals (1988).

10) M. Rühle, K. Burger, W. Mader and E. G. Evans, "Fundamental of Diffusion Bonding", Ed. Y. Ishida, Elsevier (1987). 